Author affiliations and support information (if applicable) appear at the end of this article.

Published at jco.org on March 29, 2017 E.Z. and A.C. contributed equally to this work. F.C., P.J., and C.T. contributed equally to this work.

Clinical trial information: NCT00210353. Corresponding author: Emanuele Zucca, M.D., IELSG Operation Office c/o IOSI Oncology Institute of Southern Switzerland, Ospedale San Giovanni, 6500 Bellinzona, Switzerland; e-mail: ielsg@eoc.ch.

(C) 2017 by American Society of Clinical Oncology

0732-183X/17/3517w-1905w/\$20.00

\title{
Final Results of the IELSG-19 Randomized Trial of Mucosa- Associated Lymphoid Tissue Lymphoma: Improved Event- Free and Progression-Free Survival With Rituximab Plus Chlorambucil Versus Either Chlorambucil or Rituximab Monotherapy
}

Emanuele Zucca, Annarita Conconi, Giovanni Martinelli, Reda Bouabdallah, Alessandra Tucci, Umberto Vitolo, Maurizio Martelli, Ruth Pettengell, Gilles Salles, Catherine Sebban, Armando Lopez Guillermo, Graziella Pinotti, Liliana Devizzi, Franck Morschhauser, Hervé Tilly, Valter Torri, Stefan Hohaus, Andrés J.M. Ferreri, Pierre Zachée, André Bosly, Corinne Haioun, Caterina Stelitano, Monica Bellei, Maurilio Ponzoni, Anne Moreau, Andrew Jack, Elias Campo, Luca Mazzucchelli, Franco Cavalli, Peter Johnson, and Catherine Thieblemont

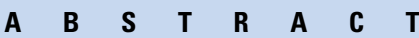

\section{Purpose}

There is no consensus on the optimal systemic treatment of patients with extranodal marginal zone lymphoma of mucosa-associated lymphoid tissue. The IELSG-19 phase III study, to our knowledge, was the first such study to address the question of first-line treatment in a randomized trial.

\section{Patients and Methods}

Eligible patients were initially randomly assigned (1:1 ratio) to receive either chlorambucil monotherapy $\left(6 \mathrm{mg} / \mathrm{m}^{2} / \mathrm{d}\right.$ orally on weeks 1 to 6,9 to 10,13 to 14,17 to 18 , and 21 to 22) or a combination of chlorambucil (same schedule as above) and rituximab $\left(375 \mathrm{mg} / \mathrm{m}^{2}\right.$ intravenously on day 1 of weeks 1, 2, 3, 4, 9, 13, 17, and 21). After the planned enrollment of 252 patients, the protocol was amended to continue with a three-arm design (1:1:6 ratio), with a new arm that included rituximab alone (same schedule as the combination arm) and with a final sample size of 454 patients. The main end point was event-free survival (EFS). Analysis of chlorambucil versus the combination arm was performed and reported separately before any analysis of the third arm.

\section{Results}

At a median follow-up of 7.4 years, addition of rituximab to chlorambucil led to significantly better EFS (hazard ratio, $0.54 ; 95 \% \mathrm{Cl}, 0.38$ to 0.77$)$. EFS at 5 years was $51 \%(95 \% \mathrm{Cl}, 42$ to 60 ) with chlorambucil alone, $50 \%(95 \% \mathrm{Cl}, 42$ to 59$)$ with rituximab alone, and $68 \%(95 \% \mathrm{Cl}, 60$ to 76$)$ with the combination $(P=.0009)$. Progression-free survival was also significantly better with the combination ( $P=.0119$ ). Five-year overall survival was approximately $90 \%$ in each arm. All treatments were well tolerated. No unexpected toxicities were recorded.

\section{Conclusion}

Rituximab in combination with chlorambucil demonstrated superior efficacy in mucosa-associated lymphoid tissue lymphoma; however, improvements in EFS and progression-free survival did not translate into longer overall survival.

\section{J Clin Oncol 35:1905-1912. (C) 2017 by American Society of Clinical Oncology}

\section{INTRODUCTION}

Extranodal marginal-zone B-cell lymphoma of mucosa-associated lymphoid tissue (MALT lymphoma) constitutes $8 \%$ of all non-Hodgkin lymphomas. ${ }^{1,2}$

Apart from the eradication of Helicobacter pylori as an initial treatment of early-stage gastric
MALT lymphoma, ${ }^{3}$ there is no consensus regarding optimal treatment of patients with gastric involvement who experience failure with antibiotics who have extensive disease or primary extragastric localization. ${ }^{1,4-7}$ Radiotherapy can result in long-term local control for localized lymphoma, ${ }^{8-10}$ but it is not always feasible. Up to one third of patients present with disseminated disease that involves multiple extranodal sites. ${ }^{11-14}$ 
Few single agents or combination chemotherapy regimens have been tested specifically in patients with MALT lymphomas, and most of the available data come from small, phase II studies with short follow-up that have generally tested compounds and regimens used for treating other indolent lymphomas. ${ }^{15-17}$ Rituximab has proven active in phase II studies ${ }^{18,19}$ and a study of combined bendamustine and rituximab has shown promising activity in first-line treatment. ${ }^{20}$ More intensive combination regimens are usually limited to patients with histologic transformation or those with high tumor burden. ${ }^{2,21,22}$

The International Extranodal Lymphoma Study Group 19 (IELSG-19) study is the first randomized trial to investigate systemic treatment of MALT lymphoma. The study was initially designed to compare chlorambucil alone and in combination with rituximab. After the planned enrollment, the study protocol was amended to add a third arm of treatment with rituximab alone. ${ }^{23}$ Preliminary results of the first two-arm portion of the study-rituximab plus chlorambucil versus chlorambucil-were previously published. $^{23}$ Here, we report the final results of the entire three-arm study.

\section{PATIENTS AND METHODS}

\section{Study Design}

The IELSG-19 study, an open-label, randomized phase III trial, was conducted at 78 centers in six countries according to the principles of the Declaration of Helsinki and after approval by local institutional review boards and/or ethics committees. All patients provided written informed consent. The study was initially designed to randomly compare in a 1:1 ratio chlorambucil alone (arm A, standard treatment) with combination chlorambucil plus rituximab (arm B, study treatment). After enrollment of the planned 252 patients, the protocol was amended and continued with a three-arm design. The new arm included rituximab alone (arm C, study treatment), and the random assignment ratio was changed to 1:1:6 for a final total sample size of 454 patients. Following the amended protocol, analysis of chlorambucil versus chlorambucil plus rituximab was performed before any analysis of the third arm and reported previously. ${ }^{23}$ Random assignment was stratified by primary tumor site (gastric $v$ nongastric), nodal involvement (presence $v$ absence), prior local therapy (surgery, radiation, or antibiotics $v$ nonpretreated), and International Prognostic Index (IPI) score (low and low-intermediate risk $v$ intermediatehigh and high risk).

\section{Patient Population}

Patients with MALT lymphoma-either newly diagnosed or those who experienced relapse after prior local therapy-were eligible. Central pathology review was performed. Patients with primary gastric H. pylori-positive MALT lymphomas were eligible for inclusion in cases of endoscopic and histologic evidence of disease progression at any time post- $H$. pylori eradication or for stable disease with persistent lymphoma $>1$ year after H. pylori eradication. Apart from H. pylori eradication, no prior systemic therapy was allowed. In all cases, measurable or evaluable disease, according to the National Cancer Institute International Workshop criteria, ${ }^{24}$ was required.

\section{Treatments}

Patients who were assigned to arm A received induction treatment with daily chlorambucil of $6 \mathrm{mg} / \mathrm{m}^{2}$ orally for 42 consecutive days (weeks 1 to 6). After restaging, patients with stable disease or an objective response then received chlorambucil $6 \mathrm{mg} / \mathrm{m}^{2}$ per day for 2 weeks every 4 weeks (one cycle) for up to four cycles (weeks 9 to 10,13 to 14,17 to 18 , and 21 to 22 ).
For patients who were assigned to arm B, chlorambucil was administered as in arm A. Rituximab $375 \mathrm{mg} / \mathrm{m}^{2}$ was administered intravenously according to manufacturer instructions on days $1,8,15$, and 22 during the induction phase. After restaging, rituximab was administered on day 1 of each of the subsequent chlorambucil cycles (weeks 9, 13, 17, and 21). Patients in arm $\mathrm{C}$ received rituximab alone with the same schedule used in arm B. Rituximab was provided by F Hoffmann-La Roche (Basel, Switzerland).

\section{Outcome Measures}

Primary end point was event-free survival (EFS), calculated from the date of trial registration to experience of treatment failure-including disease progression, early discontinuation of protocol treatment for any reason, or initiation of new treatment without documented progression-death as a result of any cause, or last follow-up. ${ }^{24}$ Secondary end points were complete response rate (CR), overall response rate (ORR), response duration, progression-free survival (PFS), overall survival (OS), and toxicity.

Response was assessed after the first 6 weeks of therapy and at the end of treatment. Further assessments were scheduled every 4 months for 2 years, every 6 months for the next 3 years, and then annually for at least 5 years and included physical examination, routine laboratory tests, chest $\mathrm{x}$-ray, and abdominal ultrasound. Additional imaging and/ or endoscopic studies to evaluate all initial disease sites were planned as appropriate.

Additional methodology details, including statistical analysis, sample size calculation, and toxicity assessment, were previously published. $^{23}$

\section{RESULTS}

\section{Patient Characteristics and Treatment}

Figure 1 shows the patient flow through the trial. Four hundred fifty-four patients were enrolled and randomly assigned: 151 to chlorambucil, 152 to chlorambucil plus rituximab, and 151 to rituximab. Forty-two patients - 16 in arm A, 19 in B, and seven in $\mathrm{C}$-were shown to be ineligible and were excluded after pathology review gave other diagnoses. Eleven additional patients were not evaluable-six were never treated and five because of major protocol violations. Therefore, the analyzed population included 401 patients (131 in $\operatorname{arm~A,~} 132$ in $\mathrm{B}$, and 138 in $\mathrm{C}$ ). Baseline characteristics are listed in Table 1. With the exception of a lower frequency of B symptoms in patients who were enrolled in the chlorambucil arm, there were no significant differences in the distribution of known risk factors. Details on the distribution of the anatomic sites across the three study arms are listed in Appendix Table A1 (online only).

Three hundred eighteen patients $(79 \%)$ completed the treatment program according to the protocol. Thirty-eight patients required at least one chlorambucil dose reduction, but no rituximab dose reduction was permitted. Treatment discontinuation was recorded in 61 patients; 17 patients in arm B concomitantly discontinued both drugs, 25 discontinued chlorambucil only (18 patients in arm A and seven in arm B), and 19 discontinued rituximab only (three in arm $\mathrm{B}$ and 16 in arm $\mathrm{C}$ ). This was usually a result of toxicity, disease progression, or patient preference, and withdrawal rates were not statistically different between arms. Median duration of treatment with chlorambucil was 14 weeks in arms A (range, 5 to 14 weeks) and B (range, 3 to 14 weeks). Median number of delivered rituximab doses was eight in arms B and C (range, 1 to 8 doses in both arms). 


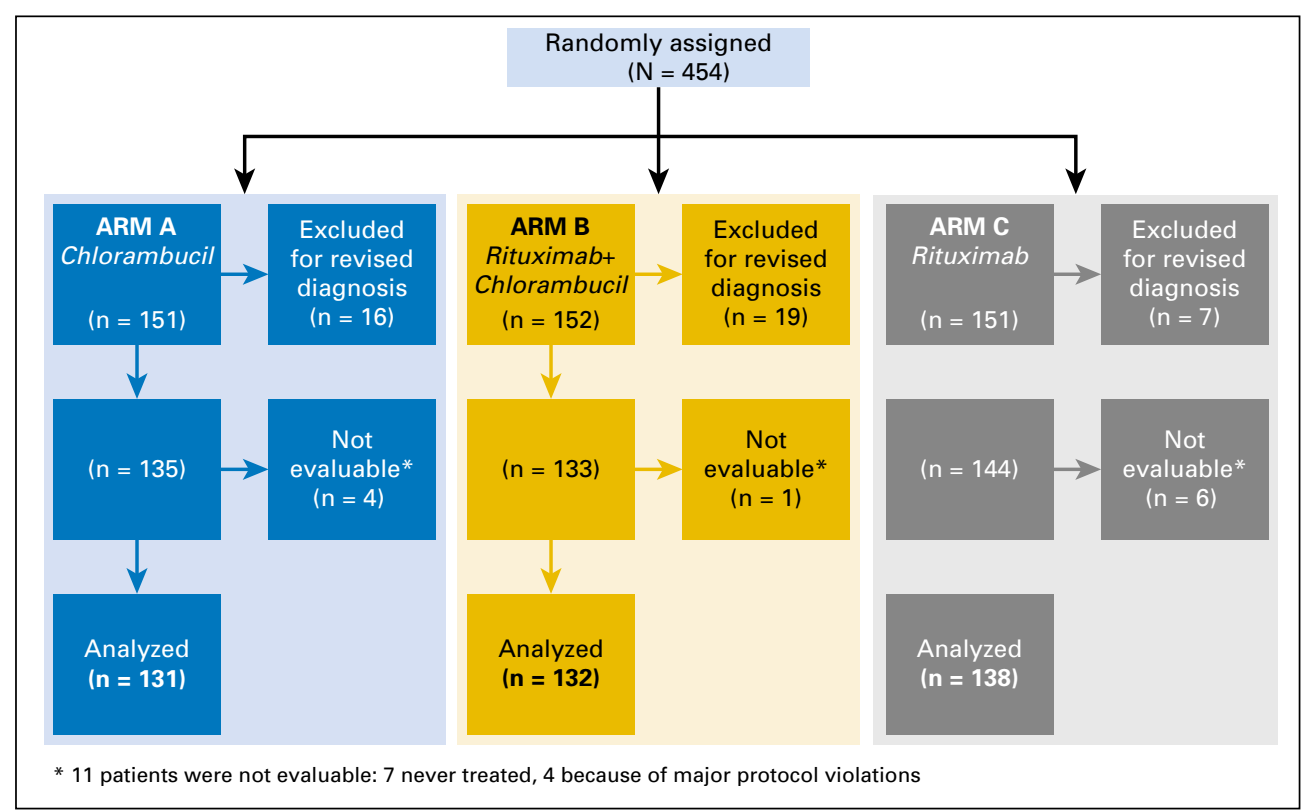

Fig 1. CONSORT diagram of study profile and patient flow. Forty-two patients were excluded after revised diagnosis, had diffuse large B-cell lymphoma (12 patients), follicular lymphoma (four patients), mantlecell lymphoma (10 patients), primary splenic marginal-zone B-cell lymphoma (nine patients), primary nodal marginal-zone B-cell lymphoma (two patients), small lymphocytic lymphoma (one patient), non-mucosa-associated lymphoid tissue (MALT) indolent lymphoma, not otherwise classifiable (two patients), and no evidence of lymphoma tissue (two patients, one with chronic gastritis and one with Crohn's disease). (*) Eleven patients were not evaluable: seven were never treated and four had major protocol violations.

\section{Treatment}

Five (1\%) of 401 patients who were treated according to protocol were never evaluated for response. One patient who was assigned to arm $B$ withdrew consent and was lost to followup, one patient assigned to arm A experienced a fatal ischemic stroke during treatment, one patient in arm B died of disease progression after histologic transformation during treatment, and two patients in arm $\mathrm{C}$ withdrew after experiencing allergic reaction to the first or second rituximab administration.

Three hundred forty-five patients ( $86 \%$; $95 \%$ CI, 82 to 89 ) achieved an objective response, with $264 \mathrm{CR}(66 \%)$ and 81 partial response $(20 \%)$. Treatment with the combination of chlorambucil plus rituximab produced better responses with significantly higher ORR and CR rates than either drug administered alone. Results of response assessment-best response according to treatment arm-are listed in Table 2. Median time to best response was 3.8 months in the whole cohort (interquartile range, 2.0 to 6.4 months) with no difference among the three arms $(P=.367)$. There was a trend toward longer remission duration in the combination arm, with $79 \%$ (95\% CI, 71 to 85$)$ of patients who achieved response in continuous remission at 5 years compared with $70 \%(95 \% \mathrm{CI}$, 60 to 78 ) and $66 \%$ (95\% CI, 56 to 74 ) in the chlorambucil and rituximab arms, respectively; however, these differences did not reach a statistical significance (Fig 2).

\begin{tabular}{|c|c|c|c|c|c|}
\hline Characteristic & $\begin{array}{l}\text { All Patients } \\
(\mathrm{N}=401)\end{array}$ & $\begin{array}{l}\text { Arm A Chlorambucil } \\
\qquad(\mathrm{n}=131)\end{array}$ & $\begin{array}{c}\text { Arm B Chlorambucil } \\
\text { Plus Rituximab }(n=132)\end{array}$ & $\begin{array}{l}\text { Arm C Rituximab } \\
\qquad(n=138)\end{array}$ & $P^{*}$ \\
\hline Median age (range), years & $61(26-81)$ & $60(26-80)$ & 59.5 (26-79) & $62.5(27-81)$ & .349 \\
\hline Male sex & $197(49.1)$ & $69(52.7)$ & $64(48.5)$ & $64(46.4)$ & .578 \\
\hline Ann Arbor stage I & $170(42.4)$ & $52(39.7)$ & $60(45.4)$ & $58(42.0)$ & .636 \\
\hline Ann Arbor stage III and IV & $175(43.6)$ & $53(40.6)$ & $59(44.7)$ & $63(45.6)$ & .662 \\
\hline$E C O G P S \geq 2$ & $6(1.5)$ & $4(3.0)$ & $1(0.7)$ & $1(0.7)$ & .293 \\
\hline Presence of B-symptoms & $42(10.5)$ & $6(4.6)$ & $20(15.1)$ & $16(11.6)$ & .017 \\
\hline Elevated serum LDH $(n=400)$ & $42(10.5)$ & $11(8.5)$ & $10(7.6)$ & $21(15.3)$ & .076 \\
\hline Extranodal sites $\geq 2$ & $123(30.7)$ & 44 (33.6) & $44(33.3)$ & $35(25.4)$ & .247 \\
\hline Nodal involvement & $142(35.4)$ & 45 (34.3) & $49(37.2)$ & 48 (34.8) & .879 \\
\hline Bone marrow involvement & $71(17.7)$ & $22(16.8)$ & $30(22.7)$ & 19 (13.8) & 148 \\
\hline Prior local therapy ${ }^{\dagger}$ & $32(8.0)$ & $14(10.7)$ & $10(7.6)$ & $8(5.8)$ & .328 \\
\hline Primary gastric siteł & $171(42.6)$ & $57(43.5)$ & $53(40.1)$ & $61(44.2)$ & .774 \\
\hline IPI risk $(n=400)$ & & & & & .795 \\
\hline Low & $229(57.2)$ & 79 (60.8) & $74(56.1)$ & $76(55.1)$ & \\
\hline Low-intermediate & $94(23.5)$ & $25(19.2)$ & $34(25.8)$ & $35(25.4)$ & \\
\hline Intermediate-high & $68(17.0)$ & $23(17.7)$ & $20(15.1)$ & $25(18.1)$ & \\
\hline High & $9(2.3)$ & $3(2.3)$ & $4(3.0)$ & $2(1.4)$ & \\
\hline
\end{tabular}

NOTE. Data are given as No. (\%) unless otherwise indicated.

Abbreviations: ECOG, Eastern Cooperative Oncology Group; IPI, International Prognostic Index; LDH, lactate dehydrogenase; PS, performance status.

${ }^{*} P$ values refer to comparison of frequencies ( $\chi^{2}$ or Fisher's exact test as appropriate) or medians (nonparametric k-sample test) in the three arms.

†ncludes previous surgery, antibiotic therapy, and/or radiation therapy.

łnncludes 10 patients with other extranodal localizations. 


\begin{tabular}{|c|c|c|c|c|c|c|c|c|}
\hline \multirow[b]{2}{*}{ Response } & \multicolumn{2}{|r|}{$\begin{array}{l}\text { All Patients } \\
(\mathrm{N}=401)\end{array}$} & \multicolumn{2}{|c|}{$\begin{array}{c}\text { Arm A } \\
\text { Chlorambucil }(n=131)\end{array}$} & \multicolumn{2}{|c|}{$\begin{array}{c}\text { Arm B } \\
\text { Chlorambucil Plus Rituximab } \\
(n=132) \\
\end{array}$} & \multicolumn{2}{|c|}{$\begin{array}{c}\text { Arm C } \\
\text { Rituximab }(n=138) \\
\end{array}$} \\
\hline & No. & $\%(95 \% \mathrm{Cl})$ & No. & $\%(95 \% \mathrm{Cl})$ & No. & $\%(95 \% \mathrm{Cl})$ & No. & $\%(95 \% \mathrm{Cl})$ \\
\hline Complete remission* & 264 & $65.8(61.0$ to 70.5$)$ & 83 & 63.4 (54.5 to 71.6$)$ & 104 & 78.8 (70.1 to 85.4$)$ & 77 & 55.8 (47.0 to 64.2$)$ \\
\hline Partial remission & 81 & 20.2 (16.4 to 24.5$)$ & 29 & 22.1 (15.3 to 30.2 ) & 21 & 15.9 (10.1 to 23.3$)$ & 31 & 22.5 (15.8 to 30.3 ) \\
\hline Stable disease & 28 & 7.0 (4.7 to 9.9 ) & 11 & 8.4 (4.3 to 14.5$)$ & 1 & 0.8 (0.02 to 4.1$)$ & 16 & $11.6(6.8$ to 18.1$)$ \\
\hline Progressive disease & 23 & 5.7 (3.7 to 8.5$)$ & 7 & 5.3 (2.2 to 10.7$)$ & 4 & $3.0(0.8$ to 7.6$)$ & 12 & 8.7 (3.0 to 12.0 ) \\
\hline Not assessed & 5 & 1.3 (0.4 to 2.9$)$ & 1 & 0.8 (0.02 to 4.2$)$ & 2 & $1.5(0.2$ to 5.4$)$ & 2 & $1.5(0.2$ to 5.1$)$ \\
\hline Overall response rate * & 345 & 86.0 (82.2 to 89.3 ) & 112 & 85.5 (78.3 to 91.0$)$ & 125 & 94.7 (89.4 to 97.8 ) & 108 & 78.3 (70.4 to 84.8 ) \\
\hline
\end{tabular}

\section{Time-Related End Point Analysis}

Median follow-up of the entire study cohort $(\mathrm{N}=401)$ was 7.4 years (interquartile range, 5.6 to 9.7 years) and, as a result of the later addition of the third arm, it was longer in arms A and B (9.3 years; interquartile range, 6.8 to 10.3 years) than in arm C (5.7 years; interquartile range, 4.8 to 6.5 years).

Median EFS, the main end point of the study, was 8.6 years in the whole cohort, but was significantly shorter for patients who were treated with chlorambucil alone (5.1 years) or with rituximab alone (5.6 years) compared with those who received rituximab plus chlorambucil (median EFS not reached; $P=.0009$ ). Compared with chlorambucil alone, addition of rituximab resulted in significant reduction of the risk of EFS events (hazard ratio [HR], $0.54 ; 95 \% \mathrm{CI}, 0.38$ to 0.77 ), whereas rituximab alone showed a nearly identical risk (HR, $0.97 ; 95 \%$ CI, 0.69 to 1.35 ). The 5 -year EFS in patients who were treated with combination therapy was $68 \%$ (95\% CI, 60 to 76 ), 51\% in those who received chlorambucil alone ( $95 \%$ CI, 42 to 60$)$, and $50 \%$ in those who were treated with rituximab alone (95\% CI, 42 to 59; Fig 3A).

Median PFS was significantly better $(P=.0119)$ in patients who were treated with combination therapy: median not reached versus 8.3 years and 6.9 years for chlorambucil and rituximab alone, respectively. HR for the combination arm was 0.62 (95\% CI,

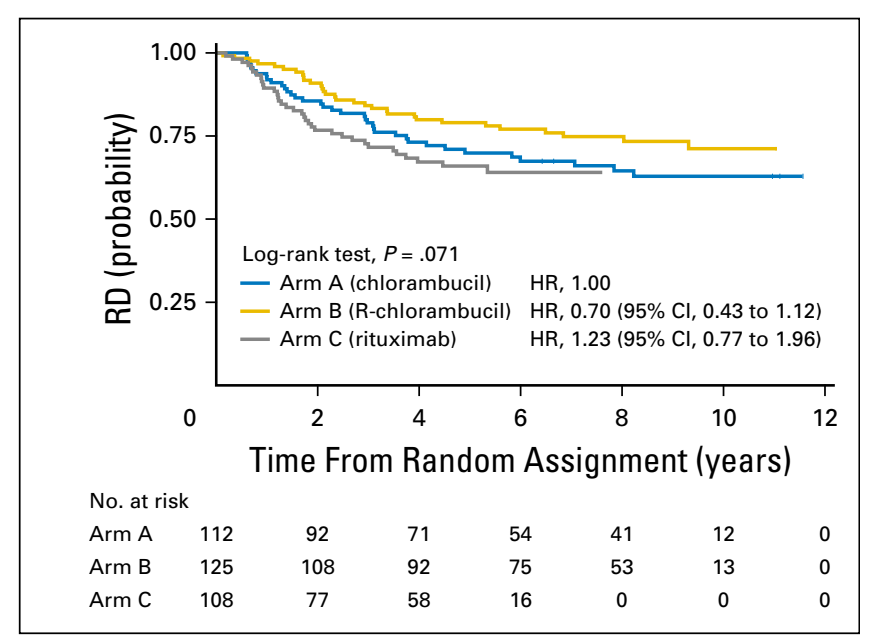

Fig 2. Kaplan-Meier estimates of response duration (RD) according to treatment arm in the 345 patients who achieved a response (partial response, $n=81$; complete response, $n=264)$. HR, hazard ratio.
0.42 to 0.93 ), whereas rituximab alone produced an outcome (HR, $1.10 ; 95 \% \mathrm{CI}, 0.76$ to 1.59 ) that was similar to chlorambucil alone (Fig 3B). The 5-year PFS in patients who were treated with combination therapy was also superior $(72 \% ; 95 \% \mathrm{CI}, 63$ to 79$)$ to that after chlorambucil (59\%; $95 \% \mathrm{CI}, 50$ to 68 ) or rituximab (57\%; 95\% CI, 48 to 65 ).

Overall, 58 patients-20 in arm A, 25 in arm B, and 13 in arm C-have died. Causes of death are described in Table 3. There was no significant difference in OS $(P=.464)$ between treatment arms (Fig 3C). The 5-year OS rate was $90 \%$ (95\% CI, 83 to 94 ) in patients who were treated with combination therapy, $89 \%$ after chlorambucil alone ( $95 \% \mathrm{CI}, 82$ to 93 ), and $92 \%$ after rituximab (95\% CI, 86 to 96 ).

Histologic transformation during the trial was reported in 10 patients (two in arm A, six in arm B, and two in arm C), and six have died (four of six patients as a result of disease progression of aggressive lymphoma). Second primary malignancies were reported in 34 patients ( 14 in $\operatorname{arm} \mathrm{A}$, nine in $\operatorname{arm} \mathrm{B}$, and 11 in arm C; $P=.512$ ): 27 solid tumors, four second B-cell neoplasms (one acute lymphoblastic leukemia, one chronic lymphocytic leukemia, and one mantle cell lymphoma), and three myeloid neoplasms.

\section{Impact of Patient Characteristics on Outcome}

In univariate analysis, IPI score and the presence of lymph node involvement demonstrated a statistically significant effect on EFS, PFS, and OS in the whole cohort, whereas primary gastric origin had an impact only on EFS and PFS. Conversely, there was no impact for prior local treatment (Appendix Table A2, online only). In multivariate analysis of EFS and PFS (Cox proportional hazards regression model that included treatment in arm $B$ and the stratification factors that had statistical significance at univariate analysis), the type of treatment remained significantly associated with EFS and PFS after controlling for nodal involvement, IPI group, and primary site (Appendix Table A3, online only). In a similar Cox proportional hazards regression model for OS — excluding primary anatomic site-only the IPI group retained a significant impact (Appendix Table A3).

In addition to better EFS and PFS, the CR rate was also significantly $(P=.015)$ higher in gastric $(72 \%$; $95 \% \mathrm{CI}, 65$ to 79$)$ versus primary nongastric lymphomas (61\%; $95 \% \mathrm{CI}$, 54 to 67 ); however, the gastric lymphoma group had a significantly higher rate of patients with localized disease (stage I disease in $60 \% v 30 \%$; $P<.001$ ), whereas the nongastric group comprised a variety of 
A

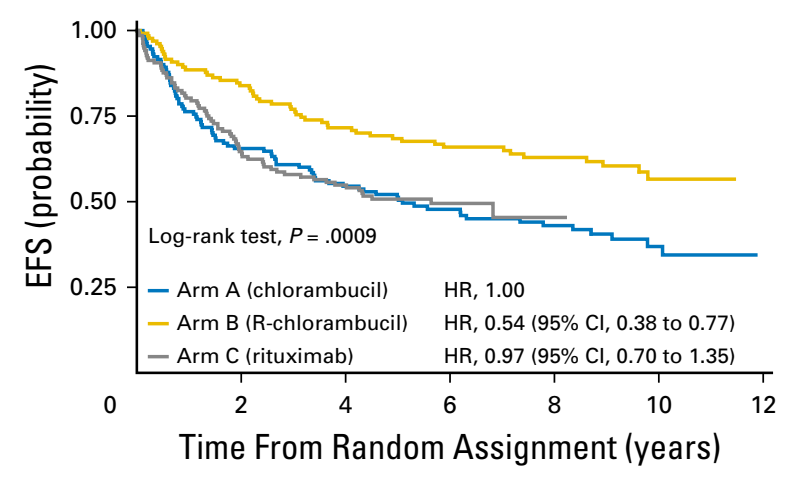

No. at risk:

$\begin{array}{cccccccc}\text { Arm A } & 131 & 85 & 68 & 53 & 41 & 16 & 0 \\ \text { Arm B } & 132 & 109 & 93 & 76 & 58 & 23 & 0 \\ \text { Arm C } & 138 & 87 & 69 & 30 & 2 & 0 & 0\end{array}$

C

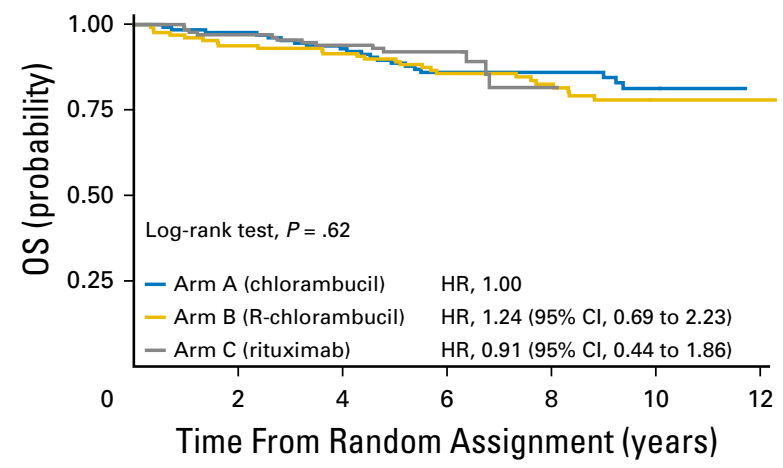

B

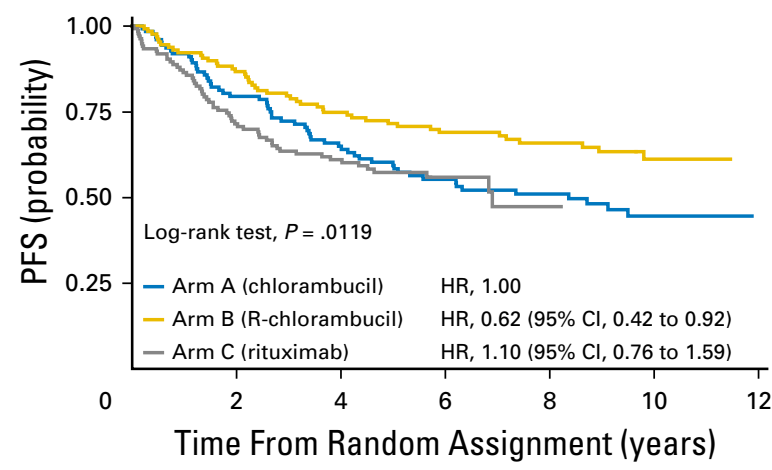

No. at risk:

$\begin{array}{cccccccc}\text { Arm A } & 131 & 89 & 70 & 53 & 42 & 16 & 0 \\ \text { Arm B } & 132 & 110 & 94 & 77 & 59 & 23 & 0 \\ \text { Arm C } & 138 & 90 & 71 & 31 & 2 & 0 & 0\end{array}$

$\begin{array}{lccccccc}\text { No. at risk: } & & & & & & & \\ \text { Arm A } & 131 & 126 & 116 & 92 & 79 & 37 & 0 \\ \text { Arm B } & 132 & 121 & 118 & 95 & 77 & 35 & 1 \\ \text { Arm C } & 138 & 130 & 118 & 50 & 3 & 0 & 0\end{array}$

Fig 3. Kaplan-Meier survival curves according to treatment received for (A) event-free survival (EFS), (B) progression-free survival (PFS), and (C) overall survival (OS). HR, hazard ratio.

anatomic primary localizations (Appendix Table A1) with diverse outcomes (Appendix Fig A1, online only). Nevertheless, a significantly higher CR rate was achieved with combination therapy in both primary gastric ( $91 \% v 61 \%$ after chlorambucil and $67 \%$ after rituximab; $P=.001$ ) and primary nongastric MALT lymphomas (72\% v 62\% after chlorambucil and 48\% after rituximab; $P=.008)$.

\begin{tabular}{|c|c|c|c|c|}
\hline Cause of Death & $\begin{array}{c}\text { All Patients } \\
\text { (58 of } 401 ; 14.5 \%)\end{array}$ & $\begin{array}{c}\text { Arm A } \\
\text { Chlorambucil (20 of 131; 15.3\%) }\end{array}$ & $\begin{array}{c}\text { Arm B } \\
\text { Chlorambucil Plus Rituximab } \\
(25 \text { of } 132 ; 18.9 \%)\end{array}$ & $\begin{array}{c}\text { Arm C } \\
\text { Rituximab (13 of } 138 ; 9.4 \%)^{*}\end{array}$ \\
\hline Lymphoma progression & $14(24.1)$ & $6(30.0)$ & $5(20.0)$ & $3(23.1)$ \\
\hline Second tumor & 17 (29.3) & $7(35.0)$ & $5(20.0)$ & $5(38.4)$ \\
\hline Transformed lymphoma & $4(6.9)$ & $0(0)$ & $4(16.0)$ & $0(0)$ \\
\hline Infection & $4(6.9)$ & $1(5.0)$ & $2(8.0)$ & $1(7.7)$ \\
\hline Respiratory failure & $4(6.9)$ & $1(5.0)$ & $2(8.0)$ & $1(7.7)$ \\
\hline Stroke & $4(6.9)$ & $1(5.0)$ & $1(4.0)$ & $2(15.4)$ \\
\hline Trauma & $1(1.72)$ & $0(0)$ & $1(4.0)$ & $0(0)$ \\
\hline Deep venous thrombosis & $1(1.72)$ & $1(5.0)$ & $0(0)$ & $0(0)$ \\
\hline Unknown & 9 (15.5) & $3(15.0)$ & $5(20.0)$ & $1(7.7)$ \\
\hline Total deaths & $58(100)$ & $20(34.5)$ & $25(43.1)$ & $13(22.4)$ \\
\hline
\end{tabular}


With respect to the primary end point of the study, a significantly longer EFS in patients who were treated with the combination of rituximab and chlorambucil was evident in both gastric $(P=.002)$ and nongastric $(P=.022)$ patients as well as in those with $(P=.0054)$ or without $(P=.0094)$ lymph node involvement and those with low and low-intermediate IPI $(P=.0005)$ but not in those with unfavorable IPI scores (Appendix Table A4, online only). As expected, patients with stage I disease had significantly better treatment outcome (Appendix Table A5, online only).

\section{Safety}

The safety population comprised all 401 patients who were treated according to protocol. Hematologic toxicity, as expected, was more frequent in the combination arm (Table 4); however, all treatments were well tolerated. A low number of adverse events was reported, with no unexpected differences between treatment arms. Nonhematologic adverse effects that occurred in more than five patients are also listed in Table 4, and a complete list of recorded nonhematologic toxicities is given in Appendix Table A6 (online only).

\section{DISCUSSION}

This study is the final report of the first randomized trial on the systemic treatment of MALT lymphoma. In a previous article, we reported the initial results of patients who were randomly assigned between chlorambucil and chlorambucil plus rituximab. The present analysis concerns the final results of the entire study population and includes the third study arm (rituximab alone). At the time of conception, chlorambucil alone was considered an acceptable comparator arm for a study that was aimed at evaluating the clinical benefit of adding rituximab to chemotherapy. ${ }^{15} \mathrm{Al}-$ though rituximab as single agent was known to carry significant antitumor activity in MALT lymphomas, ${ }^{18}$ the efficacy of chemoimmunotherapy had never been formally tested in this disease.

Sample size was calculated on a $20 \%$ difference in EFS, assuming that OS would likely not be affected in an indolent disease and that the required benefit in terms of EFS must be substantial to justify the additional cost that is associated with use of rituximab. ${ }^{23}$

In this study, addition of rituximab to chlorambucil resulted in improved remission quality-measured by ORR and CR rate- and led to significantly prolonged EFS and PFS. As expected, differences in EFS, PFS, and response rate have not yet translated into improved OS, likely as a result of effective second treatment options in indolent disease (Appendix Tables A7-A8, online only). Synergism in anticancer drug combinations can be formally assessed only in preclinical studies; however, it is worth noting that this is the only controlled clinical trial to date that compared chemotherapy alone with the combination of rituximab and chemotherapy or rituximab alone. With respect to the main study end point, observed improvement in EFS (46\% reduction in HR, with $95 \%$ CI ranging from $23 \%$ to $62 \%$ ) suggests that clinical synergy of the drug combination may be present. This benefit was confirmed in multivariate analysis of EFS and PFS, which also showed that IPI and the presence of lymph node involvement are associated with outcome (Appendix Table A3).

As the only randomized study that has specifically addressed MALT lymphoma, these results can be considered a benchmark for future trials in this entity. Lack of OS difference between arms has also provided evidence for the use of rituximab alone as initial therapy to delay or avoid the long-term risks of chemotherapy and radiotherapy.

\begin{tabular}{|c|c|c|c|c|c|c|c|c|c|c|c|c|}
\hline \multirow[b]{2}{*}{ Adverse Event } & \multicolumn{4}{|c|}{$\begin{array}{c}\text { Arm A } \\
\text { Chlorambucil }(n=131)\end{array}$} & \multicolumn{4}{|c|}{$\begin{array}{c}\text { Arm B } \\
\text { Chlorambucil Plus Rituximab }(n=132)\end{array}$} & \multicolumn{4}{|c|}{$\begin{array}{c}\text { Arm C } \\
\text { Rituximab }(n=138)\end{array}$} \\
\hline & G1 & G2 & G3 & G4 & G1 & $\mathrm{G} 2$ & G3 & G4 & G1 & $\mathrm{G} 2$ & G3 & G4 \\
\hline \multicolumn{13}{|l|}{ Hematologic toxicity } \\
\hline Leukopenia & 4 & 5 & 2 & - & 2 & 9 & 5 & - & - & - & 1 & - \\
\hline Neutropenia & 3 & 3 & - & 2 & 4 & 3 & 10 & 9 & - & - & 2 & - \\
\hline Lymphocytopenia & - & 2 & 2 & - & - & 1 & 1 & 2 & - & - & - & - \\
\hline Anemia & 4 & - & 1 & - & 2 & 1 & - & - & 1 & - & 0 & - \\
\hline Thrombocytopenia & 2 & 3 & 1 & - & 2 & 2 & 2 & - & 1 & - & - & - \\
\hline Febrile neutropenia & - & - & - & - & - & - & 3 & - & - & - & - & - \\
\hline \multicolumn{13}{|l|}{ Nonhematologic } \\
\hline Fatigue & 12 & 4 & - & - & 11 & 2 & - & - & 12 & 4 & - & - \\
\hline Fever & 1 & - & - & - & 4 & 2 & - & - & 5 & 3 & - & 1 \\
\hline Diarrhea & 1 & 1 & - & - & 5 & 1 & - & - & 3 & - & - & - \\
\hline Dyspepsia & 2 & 1 & - & - & 2 & - & 3 & - & 1 & - & - & - \\
\hline Nausea & 6 & 1 & - & - & 17 & 1 & - & - & 6 & 1 & - & - \\
\hline Stomatitis & 1 & 1 & - & - & 3 & - & - & - & 1 & - & - & - \\
\hline Skin rash & 5 & 2 & - & - & 4 & 2 & 1 & - & 3 & 1 & - & - \\
\hline Infections & 3 & 11 & 2 & 1 & 1 & 8 & 4 & - & 4 & 6 & 4 & - \\
\hline Cough & 2 & - & - & - & - & - & - & - & 4 & 2 & - & - \\
\hline Transaminase increase & - & - & 2 & 1 & - & 2 & - & 1 & 1 & - & 3 & - \\
\hline Gastric pain & 6 & 2 & 1 & - & 6 & 4 & 1 & - & 3 & 4 & - & - \\
\hline Headaches & 2 & - & - & - & 2 & 2 & - & - & 3 & 2 & - & - \\
\hline IR symptoms & - & - & - & - & 15 & 4 & 1 & 1 & 10 & 8 & 2 & - \\
\hline
\end{tabular}


In this study, patients with primary gastric localization, a stratification criterion, achieved better CR rate and EFS than did those with nongastric lymphoma. The value of unplanned analysis of patient subsets is debatable, and this finding does not necessarily indicate that gastric MALT lymphoma represents a distinct disease. The patients with gastric lymphoma who were enrolled in the study, compared with those with extragastric localizations, had a significantly higher rate of stage I disease, which may explain the different results. Moreover, extragastric sites comprise different anatomic primary localizations that may have different clinical outcomes, which has also been pointed out by a study of the SEER database. ${ }^{25}$ The current study is underpowered to address the clinical relevance of any individual anatomic localizations. Nevertheless, the benefit of combination therapy on the main study end point-EFS — was statistically significant in both gastric and nongastric MALT lymphomas.

All treatments were well tolerated and no unexpected adverse effects were recorded. To date, no clinically significant differences in acute and long-term toxicity have been observed between arms, despite the expected occurrence of infusion-related symptoms in the rituximab-containing arms, as well as increased the number of patients with grade 3 and 4 neutropenia in the combination arm (Table 4). This latter result did not cause a significant increase in neutropenic fever and infection rates.

A phase II study of the Spanish GELTAMO group has shown promising activity with the combination of bendamustine and rituximab for first-line systemic treatment ${ }^{20}$ of MALT lymphoma. This single-arm, phase II trial evaluated 57 patients. After a median follow-up of 43 months, EFS at 4 years was $88 \%$ (95\% CI, 74 to 95). These results seemed to be extremely good, although CIs overlap those of the IELSG-19 study. Moreover, in arm B of the IELSG-19 trial, several unfavorable clinical features were more common than in the GELTAMO study, including B symptoms and involvement of multiple extranodal sites, lymph nodes, and bone marrow. Hence, given the long natural history of this disease and the different size and design of the studies, direct comparison of these results with those of the randomized trial, which has approximately three times longer follow up, should be taken with caution. ${ }^{26}$
In conclusion, we have shown the superior efficacy of rituximab in combination with chlorambucil in treatment of MALT lymphoma. Improved EFS and PFS with little added toxicity justifies the first-line use of this regimen, and the results of this controlled clinical study may define a standard regimen for treatment of patients MALT lymphoma who are in need of systemic therapy. The lack of OS benefit, however, leaves room to consider the use of chlorambucil alone when treatment cost is a relevant issue, but also provides evidence for the use of singleagent rituximab to avoid the toxicity of chemotherapy.

\section{AUTHORS' DISCLOSURES OF POTENTIAL CONFLICTS OF INTEREST}

Disclosures provided by the authors are available with this article at jco.org.

\section{AUTHOR CONTRIBUTIONS}

Conception and design: Emanuele Zucca, Valter Torri, Franco Cavalli Provision of study materials or patients: Emanuele Zucca, Giovanni Martinelli, Reda Bouabdallah, Alessandra Tucci, Umberto Vitolo, Maurizio Martelli, Ruth Pettengel, Gilles Salles, Catherine Sebban, Armando Lopez Guillermo, Graziella Pinotti, Liliana Devizzi, Franck Morschhauser, Hervé Tilly, Stefan Hohaus, Andrés J.M. Ferreri, Pierre Zachée, André Bosly, Corinne Haioun, Caterina Stelitano, Elias Campo, Peter Johnson,

Catherine Thieblemont

Collection and assembly of data: Annarita Conconi, Caterina Stelitano, Monica Bellei

Data analysis and interpretation: Emanuele Zucca, Annarita Conconi, Giovanni Martinelli, Reda Bouabdallah, Alessandra Tucci, Umberto Vitolo, Maurizio Martelli, Ruth Pettengel, Gilles Salles, Catherine Sebban, Armando Lopez Guillermo, Graziella Pinotti, Liliana Devizzi, Franck Morschhauser, Hervé Tilly, Valter Torri, Stefan Hohaus, Andrés J.M. Ferreri, Pierre Zachée, André Bosly, Corinne Haioun, Maurilio Ponzoni, Anne Moreau, Andrew Jack, Elias Campo, Luca Mazzucchelli, Peter Johnson, Catherine Thieblemont

Manuscript writing: All authors

Final approval of manuscript: All authors

Accountable for all aspects of the work: All authors

\section{REFERENCES}

1. Zucca E, Bertoni F, Yahalom J, et al: Extranodal marginal zone B-cell lymphoma of mucosaassociated lymphoid tissue (MALT lymphoma), in Armitage J, Mauch M, Harris NL, et al (eds): NonHodgkin Lymphomas (ed 2). Philadelphia, PA, Lippincott Williams \& Wilkins, 2010, pp 232-253

2. Thieblemont $\mathrm{C}$ : Clinical presentation and management of marginal zone lymphomas. Hematology Am Soc Hematol Educ Program 2005: 307-313, 2005

3. Zullo A, Hassan C, Cristofari F, et al: Effects of Helicobacter pylori eradication on early stage gastric mucosa-associated lymphoid tissue lymphoma. Clin Gastroenterol Hepatol 8:105-110, 2010

4. Zucca $E$, Dreyling M; Gastric marginal zone lymphoma of MALT type: ESMO clinical recommendations for diagnosis, treatment and follow-up. Ann Oncol 20:113-114, 2009 (suppl 4)
5. Pinotti G, Zucca E, Roggero E, et al: Clinical features, treatment and outcome in a series of 93 patients with low-grade gastric MALT lymphoma. Leuk Lymphoma 26:527-537, 1997

6. Thieblemont $C$, Dumontet $C$, Bouafia $F$, et al: Outcome in relation to treatment modalities in 48 patients with localized gastric MALT lymphoma: A retrospective study of patients treated during 19762001. Leuk Lymphoma 44:257-262, 2003

7. Wöhrer S, Kiesewetter B, Fischbach J, et al: Retrospective comparison of the effectiveness of various treatment modalities of extragastric MALT lymphoma: A single-center analysis. Ann Hematol 93:1287-1295, 2014

8. Wirth A, Gospodarowicz M, Aleman BM, et al: Long-term outcome for gastric marginal zone lymphoma treated with radiotherapy: A retrospective, multi-centre, International Extranodal Lymphoma Study Group study. Ann Oncol 24:1344-1351, 2013

9. Aleman $B M$, Haas $R L$, van der Maazen RW: Role of radiotherapy in the treatment of lymphomas of the gastrointestinal tract. Best Pract Res Clin Gastroenterol 24:27-34, 2010

10. Goda JS, Gospodarowicz M, Pintilie M, et al: Long-term outcome in localized extranodal mucosaassociated lymphoid tissue lymphomas treated with radiotherapy. Cancer 116:3815-3824, 2010

11. Thieblemont $C$, Berger $F$, Dumontet $C$, et al: Mucosa-associated lymphoid tissue lymphoma is a disseminated disease in one third of 158 patients analyzed. Blood 95:802-806, 2000

12. Zucca E, Conconi A, Pedrinis E, et al: Nongastric marginal zone B-cell lymphoma of mucosa-associated lymphoid tissue. Blood 101:2489-2495, 2003

13. Raderer $M$, Wöhrer $S$, Streubel B, et al: Assessment of disease dissemination in gastric compared with extragastric mucosa-associated lymphoid tissue lymphoma using extensive staging: A singlecenter experience. J Clin Oncol 24:3136-3141, 2006

14. de Boer JP, Hiddink RF, Raderer $M$, et al: Dissemination patterns in non-gastric MALT Iymphoma. Haematologica 93:201-206, 2008 
15. Hammel $P$, Haioun $C$, Chaumette $M T$, et al: Efficacy of single-agent chemotherapy in low-grade B-cell mucosa-associated lymphoid tissue lymphoma with prominent gastric expression. J Clin Oncol 13: 2524-2529, 1995

16. Jäger $G$, Neumeister $P$, Brezinschek $R$, et al: Treatment of extranodal marginal zone B-cell lymphoma of mucosa-associated lymphoid tissue type with cladribine: A phase II study. J Clin Oncol 20: 3872-3877, 2002

17. Wöhrer $S$, Drach J, Hejna $M$, et al: Treatment of extranodal marginal zone B-cell lymphoma of mucosa-associated lymphoid tissue (MALT lymphoma) with mitoxantrone, chlorambucil and prednisone (MCP). Ann Oncol 14:1758-1761, 2003

18. Conconi $A$, Martinelli $G$, Thiéblemont $C$, et al: Clinical activity of rituximab in extranodal marginal zone B-cell lymphoma of MALT type. Blood 102 2741-2745, 2003
19. Martinelli G, Laszlo D, Ferreri AJ, et al: Clinical activity of rituximab in gastric marginal zone nonHodgkin's lymphoma resistant to or not eligible for anti-Helicobacter pylori therapy. J Clin Oncol 23: 1979-1983, 2005

20. Salar A, Domingo-Domenech E, Panizo C, et al: First-line response-adapted treatment with the combination of bendamustine and rituximab in patients with mucosa-associated lymphoid tissue lymphoma (MALT2008-01): A multicentre, singlearm, phase 2 trial. Lancet Haematol 1:e104-e111, 2014

21. Zucca E, Copie-Bergman $C$, Ricardi U, et al: Gastric marginal zone lymphoma of MALT type: ESMO clinical practice duidelines for diagnosis, treatment and follow-up. Ann Oncol 24:vi144-vi148, 2013 (suppl 6)

22. Dreyling $M$, Thieblemont $C$, Gallamini $A$, et al: ESMO Consensus conferences: Guidelines on malignant lymphoma. Part 2: Marginal zone lymphoma, mantle cell lymphoma, peripheral T-cell lymphoma. Ann Oncol 24:857-877, 2013

23. Zucca E, Conconi A, Laszlo D, et al: Addition of rituximab to chlorambucil produces superior eventfree survival in the treatment of patients with extranodal marginal-zone B-cell lymphoma: 5-year analysis of the IELSG-19 Randomized Study. J Clin Oncol 31:565-572, 2013

24. Cheson BD, Horning SJ, Coiffier B, et al: Report of an international workshop to standardize response criteria for non-Hodgkin's lymphomas. J Clin Oncol 17:1244, 1999

25. Olszewski AJ, Castillo JJ: Survival of patients with marginal zone lymphoma: Analysis of the Surveillance, Epidemiology, and End Results database. Cancer 119:629-638, 2013

26. Ferreri AJM: Bendamustine plus rituximab in MALT Iymphoma. Lancet Haematol 1:e88-e89, 2014

\section{Affiliations}

Emanuele Zucca and Franco Cavalli, Oncology Institute of Southern Switzerland, Bellinzona; Luca Mazzucchelli, Cantonal Institute of Pathology, Locarno, Switzerland; Annarita Conconi, Ospedale degli Infermi, Biella; Giovanni Martinelli, European Institute of Oncology; Liliana Devizzi, Fondazione Istituto Nazionale Tumori; Valter Torri, Mario Negri Institute; Andrés J.M. Ferreri, San Raffaele Scientific Institute; Maurilio Ponzoni, San Raffaele Hospital, Milan; Alessandra Tucci, Spedali Civili, Brescia; Umberto Vitolo, University-Hospital Città della Salute e della Scienza, Turin; Maurizio Martelli, Sapienza University; Stefan Hohaus, Catholic University of the Sacred Heart, Rome; Graziella Pinotti, Fondazione Macchi Hospital, Varese; Caterina Stelitano, Bianchi-Melacrino-Morelli Hospitals, Reggio Calabria; Monica Bellei, University of Modena and Reggio Emilia, Modena, Italy; Reda Bouabdallah, Institut Paoli-Calmettes, Marseille; Gilles Salles, Hospices Civils de Lyon and Université Claude Bernard Lyon-1, Pierre-Benite; Catherine Sebban, Centre Léon Bérard, Lyon; Franck Morschhauser, Claude Huriez Hospital, Lille; Anne Moreau, University Hospital of Nantes, Nantes; Hervé Tilly, Centre Henri Becquerel, Rouen; Corinne Haioun, Henri-Mondor Hospital, Paris Créteil; Corinne Haioun, UPEC, Assistance Publique-Hopitaux de Paris; Catherine Thieblemont, Assistance Publique-Hopitaux de Paris, Hôpital-Saint-Louis, Hematooncology-Université Paris Diderot, Sorbonne Paris-Cité, Paris, France; Ruth Pettengell, St George's University of London, London; Andrew Jack, St James's University Hospital, Leeds; Peter Johnson, Southampton General Hospital, Southampton, United Kingdom; Armando Lopez Guillermo and Elias Campo, Hospital Clinic, Barcelona, Spain; Pierre Zachée, ZNA Stuivenberg, Antwerp; and André Bosly, Mont-Godinne UCL, Yvoir, Belgium.

\section{Support}

Supported in part by a grant from Oncosuisse (ICP OCS-01356-03-2003) and by an unrestricted grant from Roche.

\section{Prior Presentation}

Presented in part at the 12th International Conference on Malignant Lymphoma, Lugano, Switzerland, June 19-22, 2013. 


\section{AUTHORS' DISCLOSURES OF POTENTIAL CONFLICTS OF INTEREST}

Final Results of the IELSG-19 Randomized Trial of Mucosa-Associated Lymphoid Tissue Lymphoma: Improved Event-Free and Progression-Free Survival With Rituximab Plus Chlorambucil Versus Either Chlorambucil or Rituximab Monotherapy

The following represents disclosure information provided by authors of this manuscript. All relationships are considered compensated. Relationships are self-held unless noted. I = Immediate Family Member, Inst = My Institution. Relationships may not relate to the subject matter of this manuscript. For more information about ASCO's conflict of interest policy, please refer to www.asco.org/rwc or ascopubs.org/jco/site/ifc.

Emanuele Zucca

Honoraria: Roche, Celgene, Janssen Pharmaceuticals

Consulting or Advisory Role: Roche, Celgene, Janssen Pharmaceuticals, Gilead Sciences, Takeda, Abbvie

Research Funding: Roche (Inst), Mundipharma (Inst), Celgene (Inst) Travel, Accommodations, Expenses: Roche, Janssen Pharmaceuticals, Gilead Sciences

Annarita Conconi

Travel, Accommodations, Expenses: Celgene, Roche

Giovanni Martinelli

No relationship to disclose

Reda Bouabdallah

No relationship to disclose

Alessandra Tucci

No relationship to disclose

Umberto Vitolo

No relationship to disclose

Maurizio Martelli

No relationship to disclose

Ruth Pettengel

No relationship to disclose

Gilles Salles

Honoraria: Genentech, Amgen, Mundipharma, Janssen Pharmaceuticals, Bristol-Myers Squibb, Celgene, Servier, Gilead Sciences

Consulting or Advisory Role: Genentech, Gilead Sciences, Janssen

Pharmaceuticals, Celgene, Novartis, NOvimmune

Research Funding: Genentech (Inst)

Travel, Accommodations, Expenses: Genentech

Catherine Sebban

No relationship to disclose

Armando Lopez Guillermo

Consulting or Advisory Role: Genentech

Research Funding: Genentech

Graziella Pinotti

No relationship to disclose

Liliana Devizzi

No relationship to disclose

Franck Morschhauser

Honoraria: Celgene, Janssen Pharmaceuticals

Consulting or Advisory Role: Genentech, Gilead Sciences

Expert Testimony: Celgene

Hervé Tilly

Honoraria: Genentech, Janssen-Cilag

Consulting or Advisory Role: Roche, Celgene, Karyopharm Therapeutics Travel, Accommodations, Expenses: Roche

\section{Valter Torri}

No relationship to disclose

\section{Stefan Hohaus}

Travel, Accommodations, Expenses: Roche

Andrés J.M. Ferreri

Consulting or Advisory Role: Gilead Sciences, Sandoz, Celgene Speakers' Bureau: Adienne

Research Funding: Celgene, Rhizen Pharmaceuticals, Mundipharma

Pierre Zachée

No relationship to disclose

\section{André Bosly}

Consulting or Advisory Role: Roche

Speakers' Bureau: Roche

Corinne Haioun

Honoraria: Roche, Gilead Sciences, Janssen Pharmaceuticals, Celgene, Takeda

\section{Caterina Stelitano}

No relationship to disclose

\section{Monica Bellei}

No relationship to disclose

\section{Maurilio Ponzoni}

Honoraria: Celgene

Consulting or Advisory Role: Celgene

Anne Moreau

No relationship to disclose

Andrew Jack

No relationship to disclose

Elias Campo

Consulting or Advisory Role: Gilead Sciences

Patents, Royalties, Other Intellectual Property: NanoString Technologies Expert Testimony: Gilead Sciences

Luca Mazzucchelli

No relationship to disclose

Franco Cavalli

Honoraria: Janssen Pharmaceuticals, Celgene, AbbVie, Takeda Consulting or Advisory Role: Novartis, Mundipharma

Research Funding: Roche (Inst), Mundipharma (Inst), Pfizer (Inst), Novartis (Inst)

Peter Johnson

Honoraria: Bristol-Myers Squibb, Novartis, Boehringer Ingelheim Consulting or Advisory Role: Celgene, Incyte

Research Funding: Janssen-Cilag, Epizyme

Catherine Thieblemont

No relationship to disclose 


\section{Acknowledgment}

This study would have not been possible without the commitment of major cooperative trial groups (Fondazione Italiana Linfomi, Groupe d'Etude des Lymphomes de l'Adulte, United Kingdom National Cancer Research Institute, and the Grup per l'Estudi dels Limfomes de Catalunya i Balears). We acknowledge all the study investigators as well as the nursing and medical staff who looked after patients at each center. In addition, we thank Elena Porro, Cristina Morinini, Nicoletta Ielmini, Monica Bellei, Marina Cesaretti, Christelle Da Cruz, Pascale Godard, Marie-Christine Pinail, Kelly Cozens, Carol J. Tyas, Ira Jakupovic, Louisa Little, Joanne Simon, and Rita Gianascio Gianocca for the data management and secretarial assistance. We also thank the members of the Data and Safety Monitoring Board (Silvia Marsoni, Walter Mingrone, and Maria Grazia Valsecchi). We appreciated the conceptual contributions from Bruno Oesterwalder, Myriam Mendila, and Michael Wenger of F. Hoffmann-La Roche.

\section{Appendix}

\section{Study Investigators and Participating Institutes}

Recruiting centers (investigators) that contributed to the IELSG-19 trial with at least one randomly assigned patient were as follows:

\section{Belgium}

1. ZNA Stuivenberg, Antwerp, Belgium (Pierre Zachée)

2. Hematology, Mont-Godinne UCL, Yvoir, Belgium (André Bosly)

3. Saint Luc Hospital, Bruxelles, Belgium (Eric Van Den Neste)

4. Haematology, AZ St-Jan AV, Brugge, Belgium (Achiel Van Hoof)

5. Juls Bordet Institute, Bruxelles, Belgium (Dominique Bron)

6. Haematology, ULB Erasme Hospital, Bruxelles, Belgium (Alain Kentos)

7. Haematology, St Joseph, Ste Thérèse and IMTR Hospitals, Gilly, Belgium (Philippe Mineur)

8. Centre Hopitalier Notre-Dame Reine Fabiola, Charleroi, Belgium (Marc André)

\section{France}

9. Haematology, Institut Paoli-Calmettes, Marseille, France (Reda Bouabdallah)

10. Haematology, Saint Louis Hospital, Paris, France (Paulin Brice, Jean-Pierre Marolleau, Catherine Thieblemont)

11. Hospices Civils de Lyon \& Université Claude Bernard Lyon-1, Pierre-Benite, France (Bertrand Coiffier, Gilles Salles)

12. Léon Bérard Hospital, Lyon, France (Catherine Sebban)

13. Haematology Department, Claude Huriez Hospital, Lille, France (Franck Morschhauser)

14. Haematology, Centre Henri Becquerel, Rouen, France (Fabrice Jardin, Pascale Lenain, Hervé Tilly, Stéphane Lepretre)

15. Henri-Mondor Hospital, Paris Créteil, France (Corinne Haioun, Jean-Charles Delchier)

16. CHU Hôtel Dieu, Nantes, France (Béatrice Mahe)

17. Clinical haematology, CHU Le Bocage Hospital, Dijon, France (René Olivier Casasnovas)

18. Haematology, CHU Nancy-Brabois, Nancy, France (Pierre Feugier)

19. Onco-haematology, Blois Hospital, Blois, France (Philippe Rodon)

20. Lens Hospital, Lens, France (Pierre Morel)

21. Haematology, Avicienne Hospital, Bobigny, France (Pierre Fenaux)

22. Arnaud de Villeneuve Hospital, Montpellier, France (Pascal Chanez)

23. Centre René Gaudiucheau, Nates-St Herblain, France (Annick Le Mevel)

24. Necker University Hospital, Paris, France (Olivier Hermine)

Italy

25. Division of Hematology, European Institute of Oncology, Milan, Italy (Giovanni Martinelli, Daniele Laszlo, Alberto Agazzi, Fedro Peccatori, Emilia Cocorocchio, Pierfrancesco Ferrucci)

26. Haematology, Spedali Civili, Brescia, Italy (Giuseppe Rossi, Alessandra Tucci)

27. Haematology, University-Hospital Città della Salute e della Scienza, Turin, Italy (Umberto Vitolo, Lorella Orsucci, Barbara Botto)

28. Department of Cellular Biotechnologies and Hematology, Sapienza University, Rome, Italy (Maurizio Martelli) 
29. Medical Oncology, Fondazione Macchi Hospital, Varese, Italy (Graziella Pinotti, Claudio Chini, Giovanni L. Rodolfo Masera)

30. Haematology Division, Fondazione Istituto Nazionale Tumori, Milan, Italy (Liliana Devizzi, Alessandro Massimo Gianni, Paola Matteucci)

31. Haematology, Catholic University of the Sacred Heart, Rome, Italy (Stefan Hohaus, Giuseppe Leone)

32. Medical Oncology, San Raffaele Hospital, Milan, Italy (Andrés J.M. Ferreri)

33. Haematology, Bianchi-Melacrino-Morelli Hospitals, Reggio Calabria, Italy (Caterina Stelitano)

34. Department of Diagnostic, Clinical and Public Health Medicine, University of Modena and Reggio Emilia, Modena, Italy (Massimo Federico, Monica Bellei, Stefania Tonelli)

35. Haematology, G. B. Rossi Hospital, Verona, Italy (Roberta Zanotti)

36. Onco-Haematology, Guglielmo de Saliceto Hospital, Piacenza Hospital, Italy (Luigi Cavanna, Annalisa Arcari)

37. Santa Maria Nuova Hospital, Reggio Emilia, Italy (Fiorella Ilariucci)

38. Oncology, Azienda ULSS 15 "Alta Padovana" Camposampiero Hospital (Mariella Sorarù)

39. Oncology, Azienda ULSS 15 "Alta Padovana" Cittadella Hospital, Italy, (Alberto Morabito)

40. Oncology and Haematology, Humanitas Clinical Institute, Rozzano, Italy (Monica Balzarotti, Armando Santoro)

41. Haematology, S. Eugenio Hospital, Rome, Italy (Maria Christina Cox)

42. Ospedale Civile, Sassuolo, Italy (Giovanni Partesotti)

43. Haematology, Azienda ospedaliera, Siena, Italy (Francesco Lauria, Alberto Fabbri)

44. Oncologic DH, Correggio Hospital, Correggio, Italy (Alberto Bagnulo)

45. Oncology, Istituto Nazionale Ricerca Cancro, Genova, Italy (Mario Roberto Sertoli)

46. Haematology, S. Nicola Pellegrino Hospital, Trani, Italy (Giuseppe Tarantini)

\section{Spain}

47. Department of Haematology, Hospital Clinic, Barcelona, Spain (Emili Montserrat, Armando Lopez Guillermo)

48. Clinical Haematology, Santa Creu i Sant Pau Hospital, Barcelona, Spain (Javier Briones Meijide)

49. Hematology, Hospital Universitario, Salamanca, Spain (Dolores Caballero)

50. Haematology, Joan XXIII Hospital, Tarragon, Spain (Lourdes Escoda Teigell)

51. Haematology, Mataró Hospital, Barcelona, Spain (José Angel Hernández, Lluís Rodriguez)

\section{Switzerland}

52. Oncology Institute of Southern Switzerland, Bellinzona, Switzerland (Emanuele Zucca, Salvatore Grisanti, Luciano Wannesson, Michele Ciriolo, Cristina Marini, Michele Ghielmini, Oreste Mora, Franco Cavalli)

\section{United Kingdom}

53. Haematology, St George's University of London, London, United Kingdom (Ruth Pettengell)

54. Cancer research Center, Southampton General Hospital, Southampton, United Kingdom (Peter Johnson)

55. Medical Oncology, St. Bartholomew's Hospital, London, United Kingdom (Sarah Payne, Silvia Montoto, Thomas A. Lister)

56. Haematology, Royal Infirmary, Aberdeen, United Kingdom (Dominic Culligan)

57. Medical Oncology, Christie Hospital, Manchester, United Kingdom (John Radford)

58. Haematology, Royal Cornwall Hospital, Cornwall, United Kingdom (Anton Kruger)

59. Haematology, Nottingham City Hospital, Nottingham, United Kingdom (Andrew McMillan)

60. Haematology, Royal Devon and Exeter Hospital, Exeter, United Kingdom (Marylin Pocock, Claudius Rudin)

61. Haematology, Medway Maritime Hospital, Gillingham, United Kingdom (Maadh Aldouri)

62. Cancer Research Center, Weston Park Hospital, Sheffield, United Kingdom (Barry William Hancock)

63. Worchestershire Acute Hospitals NHS Trust, Worcestershire, United Kingdom (Salim Shaffek)

64. Haematology, University Hospital Aintree, Liverpool, United Kingdom (Barrie Woodcok)

65. Haematology, Royal University Hospital, Liverpool, United Kingdom (Andrew Pettitt)

66. Haematology, The Royal Marsden Hospital, London, United Kingdom (David Cunningham)

67. Oncology, James Paget Hospital, Norfolk, United Kingdom (Shalal Sadullah)

68. Clinical Oncology, Birmingham Heartlands Hospital, Birmingham, United Kingdom (Donald Milligan)

69. Haematology, Victoria Hospital, Blackpool, United Kingdom (Mac Macheta) 
70. Clinical haematology and oncology, Russel Hall Hospital, Dudley, United Kingdom (Jeff Neilson)

71. Haematology, Western General Hospital, Edinburgh, United Kingdom (Mike J. Mackie, John M. Davies)

72. Clinical Oncology, Raigmore Hospital, Inverness, United Kingdom (Peter Forsyth)

73. Mount Vernon Hospital, Northwood, United Kingdom (Kirit M. Ardeshna)

74. Haematology, Queen Elisabeth Hospital, Norfolk, United Kingdom (Jane Keidan, Peter Coates)

75. Haematology, John Radcliffe Hospital, Oxford, United Kingdom (Chris Hatton)

76. Oncology, Conquest Hospital, St Leonards, United Kingdom (Simon Guy Weston Smith)

77. Sandwell and West Birmingham Hospitals, West Bromwich, United Kingdom (Penny Stableforth)

78. Darent Valley Hospital, Dartford, United Kingdom (Raphael Ezekwesili)

\section{Pathology Expert Panel}

The following pathologists contributed to the histology review committee:

Francoise Berger (Centre Hospitalier Lyon-Sud, Université Claude Bernard, Lyon, France), Elias Campo (Pathology, Hospital Clinic, Barcelona, Spain), Christiane Copie-Bergman (Pathology Department, Hôpital Henri Mondor, Paris Créteil Cedex, France), Carlo Capella (Anatomia Patologica Università di Varese, Varese, Italy), Andrew Jack (Haematological Malignancy Diagnostic Service, St James's University Hospital, Leeds, United Kingdom), Luca Mazzucchelli (Istituto Cantonale di Patologia, Locarno, Switzerland), Anne Moreau (Department of Histopathology, University Hospital of Nantes, Nantes, France), Marco Paulli (Anatomia Patologica, Università di Pavia, Pavia, Italy), Stefano A. Pileri (Department of Hematology/Oncology, University of Bologna, Bologna, Italy), Maurilio Ponzoni (San Raffaele Hospital, Milan, Italy).

\section{Statistical Analysis}

Statistical analysis was planned and supervised by Valter Torri (Pharmacological Research Institute, Milan, Italy) and Irene Floriani (Pharmacological Research Institute, Milan, Italy). Luciano Cascione (Oncology Institute of Southern Switzerland, Bellinzona, Switzerland) also contributed to the analysis.

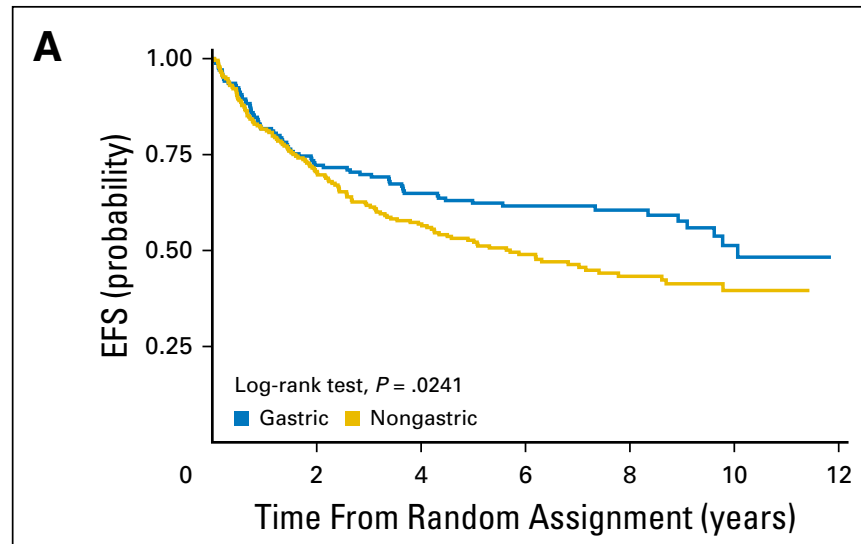

B

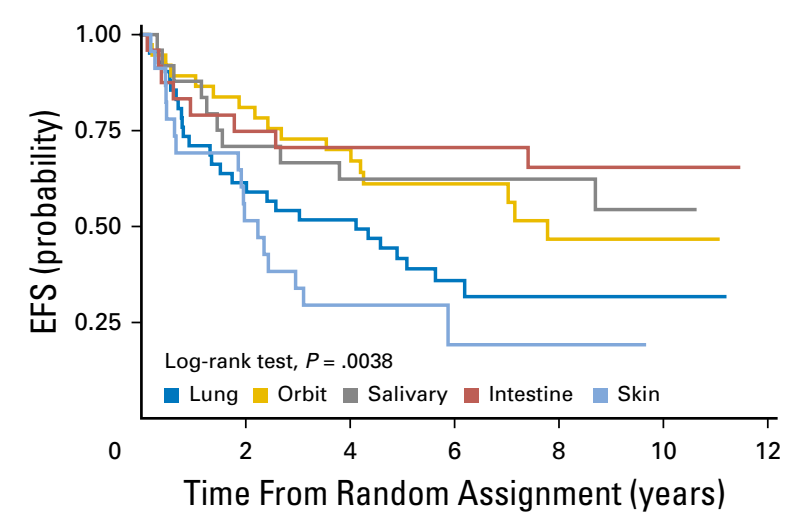

No. at risk:

$\begin{array}{llllllll}\text { Gastric } & 171 & 121 & 104 & 79 & 49 & 17 & 0 \\ \text { Nongastric } & 230 & 160 & 126 & 80 & 52 & 22 & 0\end{array}$

$\begin{array}{llllllll}\text { No. at risk: } & & & & & & \\ \square \text { Lung } & 42 & 26 & 22 & 11 & 5 & 2 & 0 \\ \text { Orbit } & 38 & 30 & 24 & 15 & 10 & 4 & 0 \\ \text { Salivary } & 25 & 17 & 15 & 11 & 10 & 5 & 0 \\ \square \text { Intestine } & 25 & 18 & 17 & 17 & 10 & 6 & 0 \\ \text { Skin } & 23 & 12 & 6 & 2 & 1 & 0 & 0\end{array}$

Fig A1. Kaplan-Meier event-free survival (EFS) curves by the primary localization of mucosa-associated lymphoid tissue (MALT) Iymphoma in (A) gastric versus extragastric disease and in $(B)$ the most frequent primary extragastric localizations. 


\begin{tabular}{|c|c|c|c|c|}
\hline Site of Localization & $\begin{array}{l}\text { All Patients } \\
(\mathrm{N}=401)\end{array}$ & Arm A Chlorambucil $(n=131)$ & $\begin{array}{c}\text { Arm B Chlorambucil } \\
\text { Plus Rituximab }(n=132)\end{array}$ & Arm C Rituximab $(n=138)$ \\
\hline Stomach & $156(38.9)$ & $50(38.2)$ & $49(37.1)$ & 57 (41.3) \\
\hline Lung & $42(10.5)$ & $19(14.5)$ & $10(7.6)$ & $13(9.4)$ \\
\hline Orbit & $38(9.5)$ & $9(6.9)$ & $11(8.3)$ & $18(13.0)$ \\
\hline Salivary glands & $25(6.2)$ & $11(8.4)$ & $10(7.6)$ & $4(2.9)$ \\
\hline Skin & $23(5.7)$ & $6(4.6)$ & $10(7.6)$ & $7(5.1)$ \\
\hline Upper airways & $13(3.2)$ & $2(1.5)$ & $6(4.5)$ & $5(3.6)$ \\
\hline Colon & $14(3.5)$ & $3(2.3)$ & $7(5.3)$ & $4(2.9)$ \\
\hline Small bowel & $11(2.7)$ & $2(1.5)$ & $5(3.8)$ & $4(2.9)$ \\
\hline Genitourinary tract & $5(1.2)$ & $2(1.5)$ & $0(0)$ & $3(2.2)$ \\
\hline Other individual sites* & $14(3.5)$ & $3(2.3)$ & 7 (5.3) & $4(2.9)$ \\
\hline Multiple sitest & $60(15.0)$ & $24(18.3)$ & $17(12.9)$ & 19 (13.8) \\
\hline
\end{tabular}

\begin{tabular}{|c|c|c|c|c|c|c|c|c|c|}
\hline & \multicolumn{3}{|c|}{ EFS } & \multicolumn{3}{|c|}{ PFS } & \multicolumn{3}{|c|}{ OS } \\
\hline & $\begin{array}{c}\text { 5-Year EFS \% } \\
(95 \% \mathrm{Cl})\end{array}$ & Median (years) & $P$ (log-rank) & $\begin{array}{c}\text { 5-Year PFS \% } \\
(95 \% \mathrm{Cl})\end{array}$ & Median (years) & $P$ (log-rank) & $\begin{array}{c}5-\text { Year OS \% } \\
(95 \% \mathrm{CI})\end{array}$ & Median (years) & $P$ (log-rank) \\
\hline Lymph node involvement & & & .0001 & & & $<.0001$ & & & .0385 \\
\hline No & 63 (56 to 68 ) & n.r. & & 69 (63 to 75$)$ & n.r. & & 93 (89 to 96$)$ & n.r. & \\
\hline Yes & 46 (37 to 54 ) & 3.4 & & 51 (42 to 59 ) & 5.6 & & 85 (78 to 90$)$ & n.r. & \\
\hline IPI & & & $<.0001$ & & & $<.0001$ & & & $<.0001$ \\
\hline Low to low-intermediate & 61 (55 to 66$)$ & 9.8 & & 68 (62 to 73 ) & n.r. & & 93 (90 to 95$)$ & n.r. & \\
\hline High-intermediate to high & 39 (28 to 49 ) & 2.7 & & 42 (31 to 53 ) & 3.3 & & 78 (67 to 86 ) & n.r. & \\
\hline Primary site & & & .0241 & & & .0013 & & & .0729 \\
\hline Gastric & 62 (54 to 69$)$ & 5.7 & & 71 (63 to 77 ) & n.r. & & 93 (88 to 96$)$ & n.r. & \\
\hline Extragastric & 53 (46 to 59$)$ & 10.1 & & 57 (50 to 63 ) & 7.0 & & 88 (83 to 92) & n.r. & \\
\hline Prior local therapy* & & & .6200 & & & .5523 & & & .3886 \\
\hline No & 57 (51 to 62$)$ & 8.7 & & 63 (58 to 68 ) & n.r. & & 90 (86 to 93 ) & n.r. & \\
\hline Yes & 58 (38 to 73$)$ & 6.3 & & 62 (41 to 77 ) & 7.0 & & 93 (41 to 77$)$ & n.r. & \\
\hline
\end{tabular}

Table A3. Cox Models Studying the Effect of Treatment Arm on Survival End Points After Controlling for Stratification Factors With a Significant Impact on Univariate Analysis

\begin{tabular}{|c|c|c|c|c|c|c|}
\hline & \multicolumn{2}{|c|}{ Event-Free Survival } & \multicolumn{2}{|c|}{ Progression-Free Survival } & \multicolumn{2}{|c|}{ Overall Survival } \\
\hline Nodal involvement & 1.66 (1.24 to 2.22$)$ & .001 & 1.78 (1.29 to 2.45$)$ & $<.001$ & 1.37 (0.81 to 2.34$)$ & .242 \\
\hline Primary extragastric site & 1.24 (0.92 to 1.67$)$ & .156 & 1.50 (1.07 to 2.10$)$ & .019 & n.a. & n.a. \\
\hline Combination arm & 0.53 (0.38 to 0.73$)$ & $<.001$ & 0.57 (0.41 to 0.82 ) & .002 & $1.30(0.77$ to 2.20$)$ & .329 \\
\hline
\end{tabular}

NOTE. All models included all patients $(N=401)$ and were statistically significant $(P>.001)$.

Abbreviations: HR, hazard ratio; IPI, international prognostic index; n.a., not applicable. 
Zucca et al

Table A4. Impact of Patient Characteristics Used for Stratification on Complete Remission and Event-Free Survival Rates Across Study Arms

\begin{tabular}{|c|c|c|c|c|c|c|c|c|}
\hline & \multicolumn{2}{|c|}{$\begin{array}{c}\text { Arm A } \\
\text { Chlorambucil }\end{array}$} & \multicolumn{2}{|c|}{$\begin{array}{c}\text { Arm B } \\
\text { Chlorambucil Plus } \\
\text { Rituximab }\end{array}$} & \multicolumn{2}{|c|}{$\begin{array}{c}\text { Arm C } \\
\text { Rituximab }\end{array}$} & \multicolumn{2}{|c|}{$P$ (univariate analysis) } \\
\hline & CR Rate (\%) & $\begin{array}{l}\text { 5-Year EFS } \\
\%(95 \% \mathrm{Cl})\end{array}$ & CR Rate (\%) & $\begin{array}{l}\text { 5-Year EFS } \\
\%(95 \% \mathrm{Cl})\end{array}$ & CR Rate (\%) & $\begin{array}{l}\text { 5-Year EFS } \\
\%(95 \% \mathrm{Cl})\end{array}$ & $\chi^{2}$ Test for $\mathrm{CR}$ & Log-Rank Test for EFS \\
\hline \multicolumn{9}{|l|}{ Lymph node involvement } \\
\hline No & 62 & 54 (43 to 64$)$ & 82 & 73 (62 to 81$)$ & 63 & 61 (50 to 70$)$ & .007 & .0094 \\
\hline Yes & 62 & 45 (30 to 59$)$ & 75 & 60 (45 to 73 ) & 44 & 31 (118 to 44$)$ & .006 & .0054 \\
\hline \multicolumn{9}{|l|}{ IPI } \\
\hline Low to low-intermediate & 67 & 57 (47 to 66$)$ & 84 & 74 (64 to 81$)$ & 56 & 52 (42 to 61$)$ & $<.001$ & .0005 \\
\hline High-intermediate to high & 40 & 29 (14 to 47$)$ & 58 & 44 (23 to 62$)$ & 59 & $44(25$ to 61$)$ & .351 & .774 \\
\hline \multicolumn{9}{|l|}{ Primary site } \\
\hline Gastric & 61 & 51 (37 to 63) & 91 & 77 (63 to 86$)$ & 67 & 60 (46 to 72 ) & .001 & .0018 \\
\hline Extragastric & 62 & 52 (40 to 63 ) & 72 & 63 (51 to 72$)$ & 48 & 43 (31 to 54$)$ & .008 & .0218 \\
\hline
\end{tabular}

Abbreviations: CR, complete remission; EFS, event-free survival; IPI, International Prognostic Index.

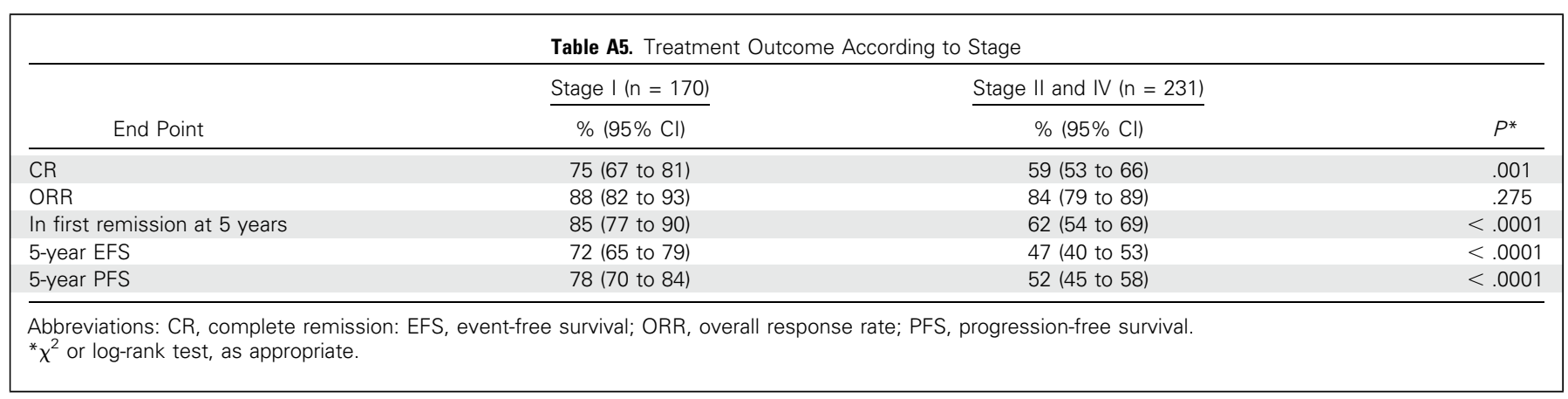




\begin{tabular}{|c|c|c|c|c|c|c|c|c|c|c|c|c|}
\hline \multirow[b]{2}{*}{ Adverse Event } & \multicolumn{4}{|c|}{$\begin{array}{c}\text { Arm A } \\
\text { Chlorambucil }(n=131)\end{array}$} & \multicolumn{4}{|c|}{$\begin{array}{c}\text { Arm B } \\
\text { Chlorambucil Plus Rituximab } \\
(\mathrm{n}=132)\end{array}$} & \multicolumn{4}{|c|}{$\begin{array}{c}\text { Arm C } \\
\text { Rituximab }(n=138)\end{array}$} \\
\hline & G1 & G2 & G3 & G4 & G1 & G2 & G3 & G4 & $\mathrm{G} 1$ & G2 & G3 & G4 \\
\hline \multicolumn{13}{|l|}{ Constitutional symptoms } \\
\hline Fatigue & 12 & 4 & - & - & 11 & 2 & - & - & 12 & 4 & - & - \\
\hline Fever & 1 & - & - & - & 4 & 2 & - & - & 5 & 3 & - & 1 \\
\hline Sweating & - & - & - & - & 1 & - & - & - & 1 & 1 & - & - \\
\hline \multicolumn{13}{|l|}{$\mathrm{Gl}$} \\
\hline Diarrhea & 1 & 1 & - & - & 5 & 1 & - & - & 3 & - & - & - \\
\hline Dyspepsia & 2 & 1 & - & - & 2 & - & 3 & - & 1 & - & - & - \\
\hline Nausea & 6 & 1 & - & - & 17 & 1 & - & - & 6 & 1 & - & - \\
\hline Vomiting & - & 2 & - & - & - & 2 & - & - & - & - & - & - \\
\hline Dysphagia & - & - & - & - & - & - & - & 1 & - & - & - & - \\
\hline Anorexia & - & - & - & - & - & - & 1 & - & 1 & 1 & - & - \\
\hline Constipation & 2 & - & - & - & 2 & - & - & - & - & - & - & - \\
\hline Stomatitis & 1 & 1 & - & - & 3 & - & - & - & 1 & - & - & - \\
\hline \multicolumn{13}{|l|}{ Dermatology/skin } \\
\hline Skin rash & 5 & 2 & - & - & 4 & 2 & 1 & - & 3 & 1 & - & - \\
\hline Pruritus/itching & 1 & 1 & - & - & - & - & 1 & - & - & - & - & - \\
\hline \multicolumn{13}{|l|}{ Infection } \\
\hline Febrile neutropenia & - & - & - & - & - & - & 3 & - & - & - & - & - \\
\hline Infection other & 3 & 11 & 2 & 1 & 1 & 8 & 4 & - & 4 & 6 & 4 & - \\
\hline \multicolumn{13}{|l|}{ Renal/genitourinary } \\
\hline Polyuria & 1 & - & - & - & - & - & - & - & - & - & - & - \\
\hline \multicolumn{13}{|l|}{ Ocular/visual } \\
\hline Tearing, watery eye (epiphora, tearing) & - & - & - & - & 1 & - & - & - & - & - & - & - \\
\hline \multicolumn{13}{|l|}{ Pulmonary/upper respiratory } \\
\hline Dyspnea & - & - & - & - & - & - & - & - & 1 & 1 & - & - \\
\hline Cough & 2 & - & - & - & - & - & - & - & 4 & 2 & - & - \\
\hline \multicolumn{13}{|l|}{ Cardiac arrhythmia } \\
\hline Palpitations & - & - & - & - & 1 & - & - & - & - & - & - & - \\
\hline Atrial fibrillation & - & - & - & - & - & - & - & 1 & - & - & - & - \\
\hline \multicolumn{13}{|l|}{ Cardiac general } \\
\hline Pericardial effusion & - & - & - & - & 1 & - & - & - & - & - & - & - \\
\hline Hypertension & - & - & - & - & - & 1 & - & - & - & - & - & - \\
\hline Neurology & & & & & & & & & & & & \\
\hline Dizziness & - & - & - & - & 1 & - & - & - & 1 & - & 1 & - \\
\hline Mood alteration, anxiety & 1 & 1 & - & - & - & - & - & - & - & - & - & - \\
\hline Syncope & - & - & 1 & - & - & - & - & - & - & - & - & - \\
\hline Paresthesia & - & - & - & - & 1 & - & - & - & 2 & 2 & - & - \\
\hline Insomnia & 1 & - & - & - & 2 & 1 & - & - & - & - & - & - \\
\hline Metabolic/laboratory & & & & & & & & & & & & \\
\hline Transaminase & - & - & 2 & 1 & - & 2 & - & 1 & 1 & - & 3 & - \\
\hline Hypophosphatemia & - & - & - & - & - & - & 1 & - & - & - & - & - \\
\hline GGT & - & 1 & - & - & - & 1 & - & - & - & - & - & - \\
\hline ALP & - & - & - & - & 1 & - & - & - & - & - & - & - \\
\hline Hypoalbuminemia & - & - & - & - & - & - & - & - & 1 & - & - & - \\
\hline Vascular & & & & & & & & & & & & \\
\hline Hemorrhage & 1 & - & - & - & 1 & - & - & - & 1 & - & 1 & - \\
\hline Pulmonary embolism (vascular) & - & - & 1 & - & - & - & - & - & - & - & - & - \\
\hline Auditory/ear & & & & & & & & & & & & \\
\hline Tinnitus & - & - & - & - & 1 & - & - & - & - & - & - & - \\
\hline Pain & & & & & & & & & & & & \\
\hline Arthralgia (pain) & - & 2 & - & - & - & - & - & - & - & - & - & - \\
\hline Bone/muscle pain & - & - & - & - & 1 & - & - & - & 2 & 2 & - & - \\
\hline Eye pain/blurred vision & - & - & - & - & - & - & - & - & 1 & - & - & - \\
\hline Gastric pain & 6 & 2 & 1 & - & 6 & 4 & 1 & - & 3 & 4 & - & - \\
\hline Headaches & 2 & - & - & - & 2 & 2 & - & - & 3 & 2 & - & - \\
\hline Pancreatitis & - & - & - & - & - & - & - & - & - & - & 1 & - \\
\hline IR symptoms & - & - & - & - & 15 & 4 & 1 & 1 & 10 & 8 & 2 & - \\
\hline
\end{tabular}


Zucca et al

Table A7. Second-Line Treatment

\begin{tabular}{|c|c|c|c|c|}
\hline & All Patients & Arm A Chlorambucil & Arm B Chlorambucil Plus Rituximab & Arm C Rituximab \\
\hline Treatment type*, No. (\%) & 134 & 46 & 36 & 52 \\
\hline None & $14(10.4)$ & $6(13.0)$ & $3(8.3)$ & $5(9.6)$ \\
\hline $\mathrm{R}$ alone & $10(7.5)$ & $6(13.0)$ & $3(8.3)$ & $1(1.9)$ \\
\hline Alkylating based & $12(8.9)$ & $2(4.4)$ & $3(8.3)$ & $7(13.4)$ \\
\hline Purine analog based & $5(3.7)$ & $1(2.2)$ & $2(5.6)$ & $2(3.8)$ \\
\hline R-bendamustine & $8(6.0)$ & $1(2.2)$ & $3(8.3)$ & $4(7.7)$ \\
\hline $\mathrm{R}$ and anthracycline based & $16(12.0)$ & $11(23.9)$ & $3(8.3)$ & 2 (3.9) \\
\hline $\mathrm{R}$ and alkylating based & $26(19.4)$ & 7 (15.2) & $3(8.3)$ & $16(30.8)$ \\
\hline Fludarabine/cyclophosphamide-R & $2(1.5)$ & $0(0.0)$ & $0(0.0)$ & 2 (3.8) \\
\hline Others & $11(8.2)$ & $3(6.5)$ & $4(11.1)$ & $4(7.7)$ \\
\hline Radiotherapy & $15(11.2)$ & $4(8.7)$ & $5(13.9)$ & $6(11.5)$ \\
\hline Unknown & $15(11.2)$ & $5(10.9)$ & $7(19.5)$ & $3(5.8)$ \\
\hline
\end{tabular}

Abbreviation: $\mathrm{R}$, rituximab.

*Alkylating-based regimens included single-agent chlorambucil or cyclophosphamide, or cyclophosphamide combined with vincristine and prednisone. Purine

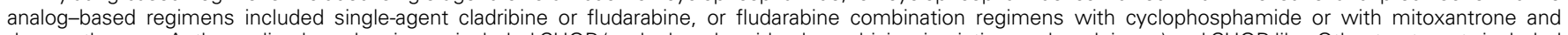

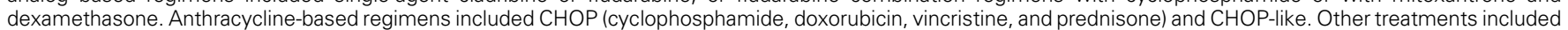
antibiotics, everolimus, bortezomib, and radioimmunotherapy with ibritumomab-tiuxetan.

\begin{tabular}{|c|c|c|c|c|}
\hline & $\begin{array}{c}\text { All } \\
\text { Patients } \\
(n=83)\end{array}$ & $\begin{array}{c}\text { Arm A } \\
\text { Chlorambucil } \\
(n=26)\end{array}$ & $\begin{array}{c}\text { Arm B Chlorambucil } \\
\text { Plus Rituximab } \\
(n=23)\end{array}$ & $\begin{array}{c}\text { Arm C } \\
\text { Rituximab } \\
(\mathrm{n}=34)\end{array}$ \\
\hline Median (years) & 2.3 & 2.7 & 2.4 & 1.6 \\
\hline $\begin{array}{l}\text { Interquartile } \\
\text { range } \\
\text { (years) }\end{array}$ & 1.3-3.9 & $1.3-5.3$ & $2.1-4.3$ & $1.0-2.8$ \\
\hline \multicolumn{5}{|c|}{$\begin{array}{l}\text { *Information on time to next treatment was not included in the follow-up case } \\
\text { report forms of the trial and could only be retrieved for } 83 \text { patients. In this small } \\
\text { subset, the difference in the time to next therapy among the three arms was } \\
\text { statistically significant (Log-rank test, } P=.014 \text { ). These results, however, should } \\
\text { be interpreted with caution due to the considerable amount of missing } \\
\text { information. }\end{array}$} \\
\hline
\end{tabular}

